\title{
Effect of Hydrated Lime and Portland Cement on Asphalt Binders using DSR
}

\author{
Muslich Sutanto ${ }^{1,2, *}$, Nura Bala ${ }^{1}$, Fahmi Al Chodri $^{3}$, and Sri Sunarjono ${ }^{3}$ \\ ${ }^{1}$ Department of Civil \& Environmental Engineering, Universiti Teknologi PETRONAS, 32610 Bandar \\ Seri Iskandar, Perak, Malaysia \\ ${ }^{2}$ Institute of Self Sustainable Building, Universiti Teknologi PETRONAS, 32610 Bandar Seri Iskandar, \\ Perak, Malaysia \\ ${ }^{3}$ Department of Civil Engineering, Universitas Muhammadiyah Surakarta, 57102 Pabelan Kartasura \\ Tromol Pos 1 Surakarta, Indonesia
}

\begin{abstract}
Bituminous binder modification has been acknowledged as one of the methods to improve asphalt pavement quality. This study is focussing on investigating the effect of Portland cement and hydrated lime on asphalt pavement of which different percentages $(4 \%, 6 \%$ and $8 \%$ by weight of bitumen binder) were added to the control $60 / 70$ pen grade bitumen. The effect of the two additives were evaluated through penetration, softening point and dynamic shear rheometer (DSR) tests. Temperature ranges of $20^{\circ} \mathrm{C}$ $-40^{\circ} \mathrm{C}$ were used for the DSR rheological testing. The results showed that addition of both hydrated lime and Portland cement had a significant influence on the binder properties. A reduction in penetration and increase in softening point temperature were observed with increase in additive content, this indicates improvement in stiffness and rutting resistance. Also, the DSR rheological analysis shows that the modified binders have higher rutting resistance.
\end{abstract}

\section{Introduction}

Service life of pavements is one of the most important issues to be addressed for economy and other reasons. Several distresses such as cracking and rutting reduces asphalt pavement lifetime, therefore, the improvement of asphalt binders in order to sustain large stresses during pavement service life is necessary. Rutting is the permanent deformation of pavements layers due to the accumulation of strains over time under the action of repetitive traffic loading on pavement $[1,2]$. Rutting deformation in asphaltic pavements leads to a serious reduction in both structural as well service life performance of the pavement. The properties of pavement materials are critical factors in determining rutting potential of the pavement. The rutting depth in pavements depends to a large extent on the stiffness of the asphaltic mixture, which in turn also depends entirely on the stiffness of the binder material $[3,4]$.

\footnotetext{
${ }^{*}$ Corresponding author: muslich.sutanto@utp.edu.my
} 
Recent increase in traffic volumes and axle loads with bitumen poor performance on different weather conditions, results in placing much emphasis in its modification to resist defects like moisture damages, deformations and fatigue cracking [5, 6]. Hydrated lime and Portland cement are adhesive binders usually used for in hot-mix asphalt mixtures. Both hydrated lime and Portland cement may be used as a filler or additive to modify asphalt binders for the purpose of improving different properties of asphalt binders and hot-mix asphalt mixtures $[7,8]$.

Different classes of polymers such as thermoplastic elastomers and plastomers were previously used to modify bitumen. The polymers are found to be good materials for bitumen modification after yielding several improvements on the modified binders [8-10]. The major benefits recorded in applying polymers are reduction in temperature sensitivity, increasing resistance to permanent deformation, higher stiffness during high temperature, good resistant to moisture, resistance to cracking at lower temperatures and longer fatigue life $[11,12]$.

Application of Portland cement effect and hydrated lime as additives on recycled cold inplace asphalt mixtures with asphalt emulsion was evaluated by Niazi et al. [13]. Both the lime (hydrated lime) and Portland cement was utilized in form of powder. The outcome of the investigation show that the strength property (Marshall stability), tensile strength, resilient modulus, moisture damage resistance as well as rutting deformation significantly improves with the increase of both additives.

The main objective of this research is to investigate the effect of hydrated lime and cement additive on the properties asphalt binder using conventional and DSR rheological tests.

\section{Materials and methods}

\subsection{Materials}

Bitumen binder grade 60/70 penetration was used for the preparation of modified binders blend in this study. Two different filler additives namely lime (hydrated lime) and Portland cement was used for the binder modification to form modified blends. The lime and cement are both obtained from local source.

\subsection{Methods}

\subsubsection{Preparations of modified binders}

The modified binders were prepared bench top multimix high shear mixer by adding various percentages $(4 \%, 6 \%$ and $8 \%)$ of Portland cement and hydrated lime by weight of bitumen binder. 80/100 pen grade binder was used for this study, additives were added to the required amount of base binder at a high shearing rate of $4000 \mathrm{rpm}$, the mixing continued for duration of 2 hours until Portland cement and hydrated lime dissolves completely on the base binder.

\subsubsection{Penetration test}

A penetration test was conducted based on ASTM D5-13 [14] specification to evaluate the consistency of the modified binders. According to the specification, the test is conducted at a temperature of $25^{\circ} \mathrm{C}$. The binder sample is subjected to an applied load of $100 \mathrm{~g}$ for duration of 5 seconds. This load application produces penetration depth in of the sample tested. The penetration depth produced is recorded as the sample penetration value. 


\subsubsection{Softening point test}

Ring and ball softening point test was conducted based on ASTM D36-14 [15] specification. Softening point test characterize and evaluates the temperature at which asphalt binder sample softens. The temperature at which bitumen binder sample cannot support a $3.5 \mathrm{~g}$ steel ball is recorded as the temperature or softening point temperature of the binder sample. During the test the binder sample is heated at a constant temperature rate of $5^{\circ} \mathrm{C} / \mathrm{min}$ throughout.

\subsubsection{Rheological analysis}

Rheological analysis was conducted using a Malvern Kinexus dynamic shear rheometer (DSR). The DSR characterize the viscoelastic rheological properties of binders especially if the binder is modified. Temperature sweep test was conducted using the DSR and the mode of loading used is controlled strain loading mode. Temperature ranges of $20-40{ }^{\circ} \mathrm{C}$ with loading frequency of $10 \mathrm{rad} / \mathrm{s}$ were used for the investigation of viscoelastic properties. The main viscoelastic parameters obtained are complex modulus $\left(\mathrm{G}^{*}\right)$ and phase angle $(\delta)$. To test each sample a melted sample of weight about $1.0 \mathrm{~g}$ is placed on the lower plate of the DSR. The parallel upper DSR plate is lowered to testing gap geometry of height of $1 \mathrm{~mm}$ or $2 \mathrm{~mm}$ plus $50 \mu \mathrm{m}$. Excess binder sample around the two plates is trimmed out completely. The final DSR is finally adjusted to the required testing gap of $1 \mathrm{~mm}$ or $2 \mathrm{~mm}$ depending on the DSR plate geometry.

\subsubsection{Aging method}

Rolling thin film oven test (RTFOT) test was performed on the binders in accordance to ASTM D2872-12e1 [16] standard specification. The RTFOT test simulates binders short term aging occurrence caused by oxidation which usually happens during mixing of binders, compaction or early stage of pavement life. For RTFOT test a binder samples of 35 grams weight were poured in to RTFOT glass containers. The containers with binder samples was then placed in the RTFOT carriage with the top opening of the containers directly facing a jet of air inside and then closed. Ageing process continues for 85 minutes with the carriage rotating at speed of $15 \mathrm{rpm}$ at an uninterrupted temperature of $163^{\circ} \mathrm{C}$

\section{Results and discussion}

\subsection{Penetration test}

Figure 1 presents the penetration test result of Portland cement and hydrated lime modified binders. As can be seen, the modified binders have lower penetration values as compared to the control binder, and the decrease in penetration is observed to be higher with increase in both additives content. This indicates that both additives have significant effect on decreasing the penetration values of the modified binders. The significant decrease in penetration values may be beneficial in improving the modified binders resistance against effects of temperature. This increases the durability and performance of the modified binders at service life stage of the pavement. Also, the significant reduction in penetration observed for the modified binders especially at higher additive content shows that higher additive content 
makes the binder to have higher stiffness which might subsequently improves the binders rutting resistance.

\subsection{Softening point test}

Figure 2 presents the softening point temperature test results for Portland cement and hydrated lime modified binders. It can be seen that the modified binders have higher softening point temperature as compared to control unmodified binder. This indicates that addition of Portland cement and hydrated lime significantly increases the stiffness of the modified binders. The softening point temperature improvement is observed to be significantly higher with increase in both additives content. Also, the significant improvement in softening point temperature for the modified binders confirms a reduction in the modified binders ability to soften easily under the influence of high temperature conditions, this will makes the binders to be more resistant against rutting deformation.

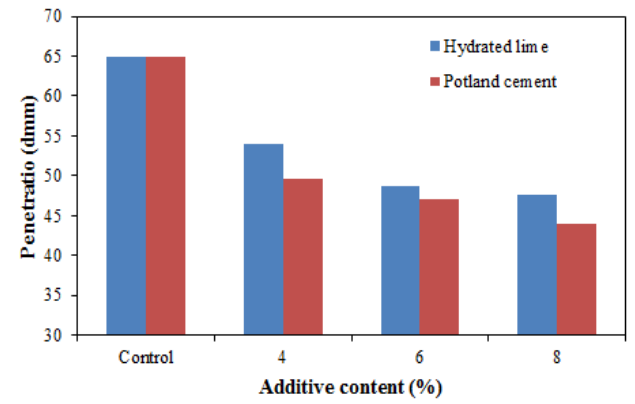

Fig.1. Penetration test

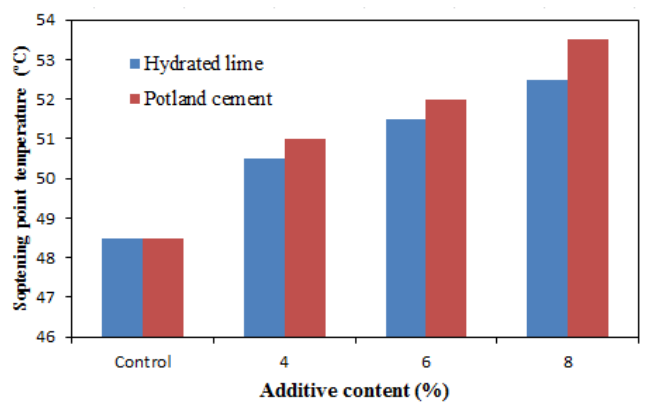

Fig. 2. Softening point temperature test

\subsection{DSR rheological analysis}

\subsubsection{Isochronal plots}

An isochronal plot is a plot of viscoelastic parameters such as complex modulus against temperature at constant loading time or frequency. Figure 3 and 4 presents the isochronal plot of complex modulus for control, Portland cement and hydrated lime modified binders. It can be seen that, the modified binders shows an increase in complex modulus values as compared to the control unmodified binder. The increase in complex modulus values is observed to be more significant with increase in both additives content. This shows that the additives have significant effect on improvement of the complex modulus. The increase in complex modulus observed in the modified binders indicates that the viscoelastic properties of the control binder were improved due to addition of Portland cement and hydrated lime, this will help in improving the stiffness of the modified binders. It can also be seen that, for the modified binders, there is slight increase in $\mathrm{G}^{*}$ at lower additive contents, but at higher additive content, greater increment in $\mathrm{G}^{*}$ values was observed, this indicates that, higher additive content resulted in better viscoelastic properties which increases binders resistance to permanent deformation. Comparing the unaged and RTFOT aged binders, it can be seen that there is significant increase in $\mathrm{G}^{*}$ values showing that aging has less effect on the modified binders. 


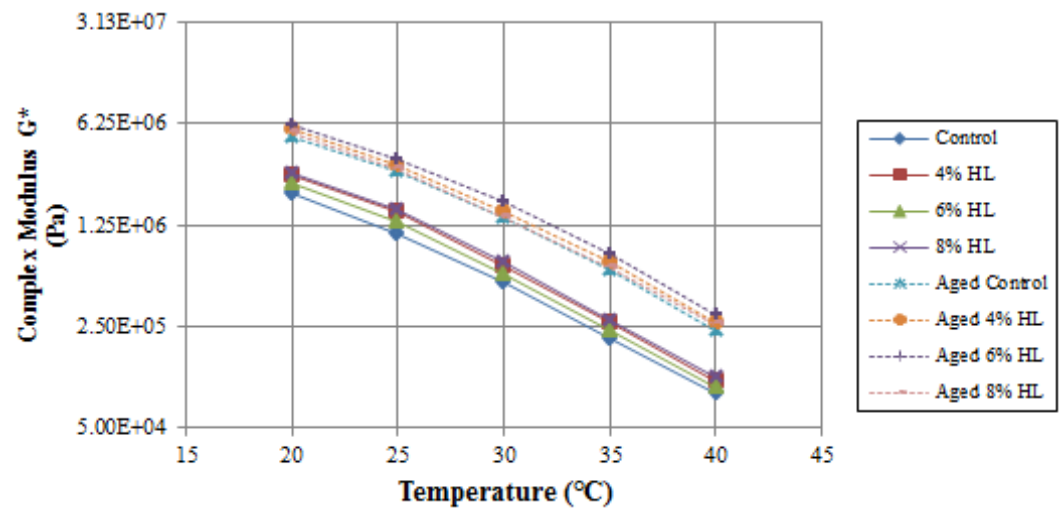

Fig. 3. Isochronal plot of complex modulus for hydrated lime

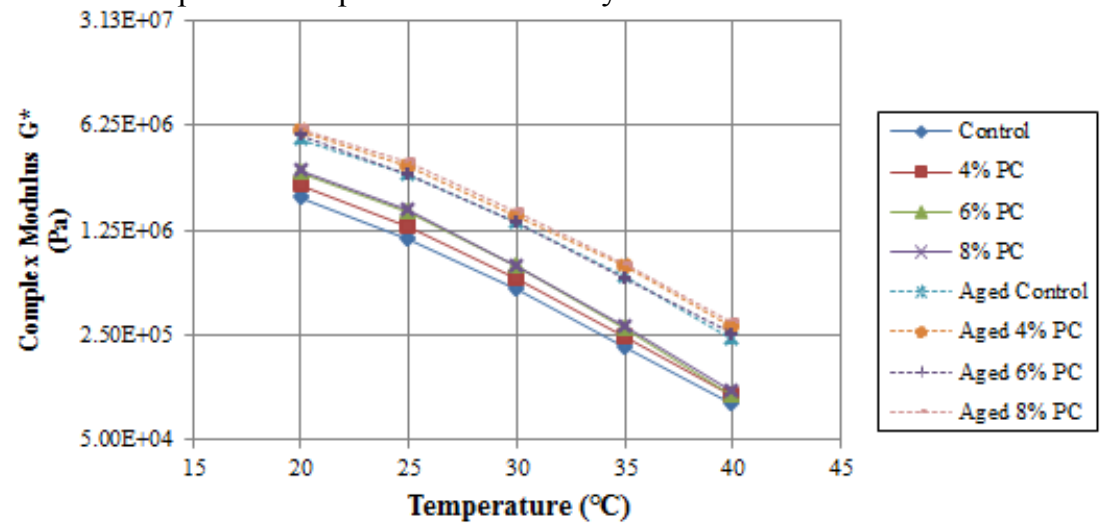

Fig. 4. Isochronal plot of complex modulus for Portland cement

Figure 5 and 6 presents the isochronal plot of phase angle for the control and modified binders. It can be observed that, the modified binders have lower phase angle values as compared to control unmodified binder. This shows that addition of both Portland cement and hydrated lime significantly causes a reduction in phase angle values of the modified binders which indicates improvement in viscoelasticity of the modified binders. Also, the decrease in phase angle values as additives were added especially at intermediate temperatures confirms the formation of improved viscoelastic modified blend which will enhances the binders performance.

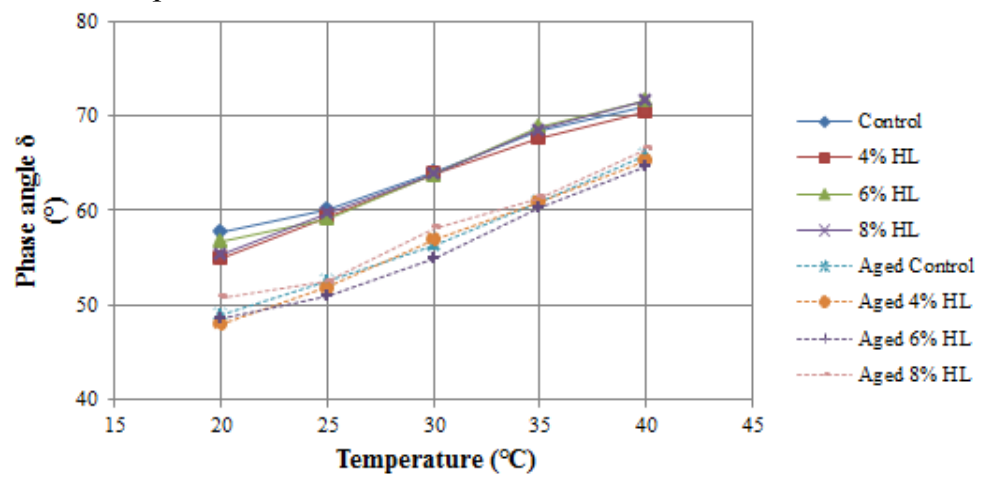

Fig. 5. Isochronal plot of phase angle for hydrated lime modified binder 


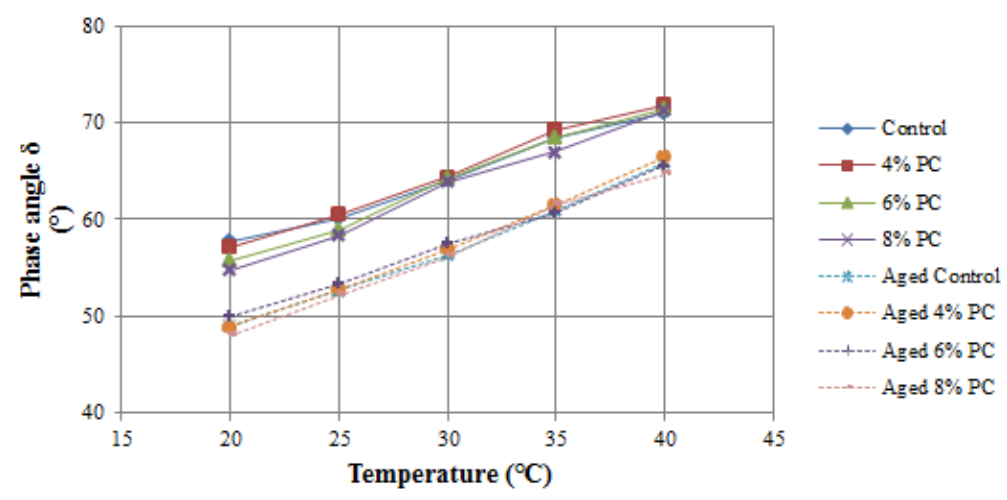

Fig. 6. Isochronal plot of phase angle for Portland cement modified binder

\subsubsection{Rutting parameter}

To estimate the modified binders resistance to rutting deformation, a ratio $\mathrm{G}^{*} / \sin \delta$ is used for the estimation as specified by Superpave specifications. Superpave specification sets a limit of $\mathrm{G}^{*} / \sin \delta \geq 1 \mathrm{kPa}$ for unaged binder and $\mathrm{G}^{*} / \sin \delta \geq 2.2 \mathrm{kPa}$ for short term aged binder [17] as the minimum required value for rutting resistance of binders. Figure 7 and 8 presents the rutting parameter $\left(\mathrm{G}^{*} / \mathrm{sin} \delta\right)$ for hydrated lime and Portland cement modified binders at different temperatures. As can be seen, both before and after RTFOT aging, the modified binders have higher $\mathrm{G}^{*} / \sin \delta$ values compared to the control binders, this indicates that the modified binders will have higher resistance to rutting deformation since higher $\mathrm{G}^{*} / \sin \delta$ values signifies better rutting resistance. Also, it can be seen that both modified binders have $\mathrm{G}^{*} / \sin \delta>1$ before aging and $\mathrm{G} * / \mathrm{sin} \delta>2.2$ after RTFOT, that is all above the minimum required value, this shows that the binders will have adequate resistance against rutting deformation.

However, it can also be seen that, after RTFOT aging, the modified binders shows significant increase in rutting parameter $\left(\mathrm{G}^{*} / \mathrm{sin} \delta\right)$ at all temperature ranges. The significant increase in rutting parameter indicates that aging has less effect on the modified binders. That is the additives hydrated lime and Portland cement can delay aging on the binders since aging in asphalt binders is inevitable.

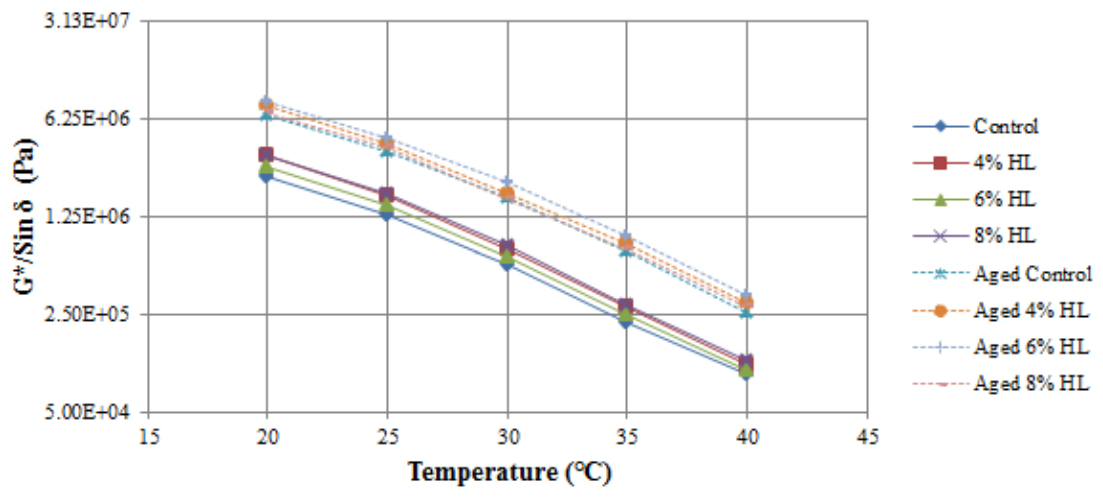

Fig. 7. Rutting parameter of hydrated lime modified binders 


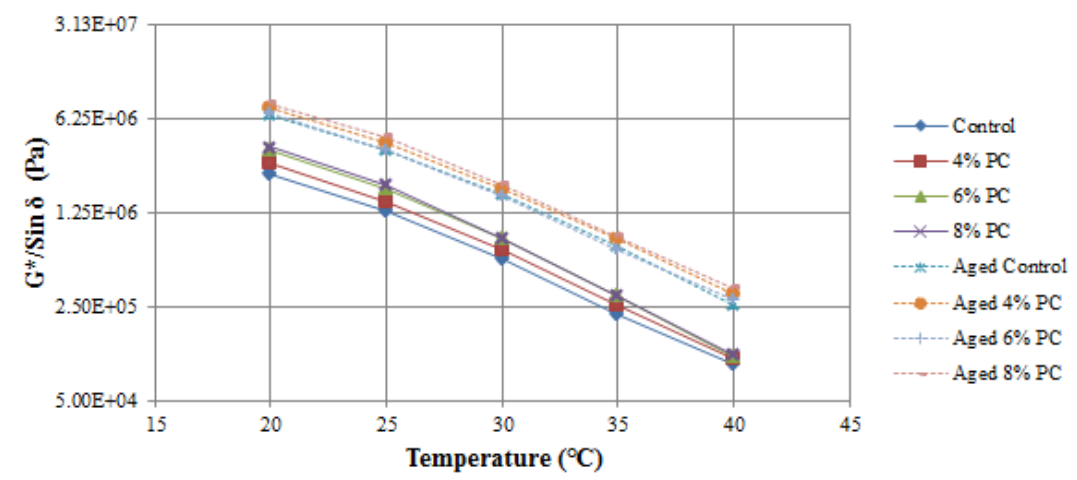

Fig. 8. Rutting parameter of Portland modified binders

\section{Conclusions}

Based on the results in this study, the following conclusions can be drawn:

- Conventional test result indicates that, the modified binders show a reduction in penetration and increase in softening point temperature. This indicates improvement in hardness and resistance to temperature effects in the modified binders.

- DSR rheological analysis shows that addition of hydrated lime and Portland cement improves the viscoelastic rheological properties of the modified binders at al temperatures tested.

- Estimations of aging and rutting deformation indicates that, the modified binders will have significantly higher resistant to deformation and aging has less effect on the modified binders as compared to control unmodified binder.

\section{Acknowledgement}

The authors would like to thank Universiti Teknologi PETRONAS for the financial support in this research through the Short Term Internal Research Fund (STIRF). We would also acknowledge Universitas Muhammadiyah Surakarta for the collaboration through Research Attachment Program at Universiti Teknologi PETRONAS.

\section{References}

1. A. Khodaii. and A. Mehrara, Evaluation of permanent deformation of unmodified and SBS modified asphalt mixtures using dynamic creep test. Construction and Building Materials, 23, 7, p. 2586-2592(2009).

2. N .Bala, et al., Rheological and rutting evaluation of composite nanosilica/polyethylene modified bitumen. Proceedings of the 7 th International Conference on Key Engineering Materials (ICKEM 2017) held between 11th to 13th March 2017, Penang Malaysia. IOP Conference Series: Materials Science and Engineering, 201, 1(2017)

3. R. Imaninasab, Effect of granular polymers on rutting performance of SMA with respect to modification process. Construction and Building Materials. 130: p. 64-72 (2017). 
4. N. Bala, I. Kamaruddin, and M. Napiah, The Influence of Polymer on Rheological and Thermo Oxidative Aging Properties of Modified Bitumen Binders. Jurnal Teknologi, 79, 6 p. 69-73 (2017).

5. Sengoz, B. and G. Isikyakar, Evaluation of the properties and microstructure of SBS and EVA polymer modified bitumen. Construction and Building Materials, 22 9: p. 1897-1905(2008).

6. N. Bala, M. Napiah, and I. Kamaruddin, Effect of nanosilica particles on polypropylene polymer modified asphalt mixture performance. Case studies in construction materials, 8 p. 447-454 (2018).

7. G.G Al-Khateeb, and N.M. Al-Akhras, Properties of Portland cement-modified asphalt binder using Superpave tests. Construction and Building Materials, 25 2: p. 926-932 (2011).

8. N. Bala, I. Kamaruddin, and M. Napiah, THE INFLUENCE OF POLYMER ON RHEOLOGICAL AND THERMO OXIDATIVE AGING PROPERTIES OF MODIFIED BITUMEN BINDERS. Jurnal Teknologi, 79, 6 p. 69 - 73(2017).

9. G.D. Airey, Rheological properties of styrene butadiene styrene polymer modified

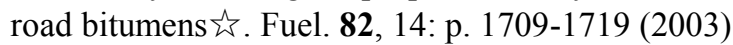

10. N. Bala, et al., Polymer Nanocomposite-Modified Asphalt: Characterisation and Optimisation Using Response Surface Methodology. Arabian Journal for Science and Engineering, p. 1-11(2018).

11. J. Zhu, B. Birgisson, and N. Kringos, Polymer modification of bitumen: Advances and challenges. European Polymer Journal, 54: p. 18-38 (2014).

12. N. Bala, M. Napiah, and I. Kamaruddin, Nanosilica composite asphalt mixtures performance-based design and optimisation using response surface methodology. International Journal of Pavement Engineering, p. 1-12(2018).

13. Y. Niazi, and M. Jalili, Effect of Portland cement and lime additives on properties of cold in-place recycled mixtures with asphalt emulsion. Construction and Building Materials, 233 p. 1338-1343 (2009).

14. M, A.S.T., "ASTM D5-13 "Standard Test Method for Penetration of Bituminous Materials". ASTM International, 2013. 04, 03.

15. M, A.S.T., "ASTM D36-14" Standard Test Method for Softening Point of Bitumen (Ring and Ball Apparatus". ASTM International, 2014. 04, 04.

16. M, A.S.T., "ASTM D2872-12 "Standard Test Method for Effect of Heat and Air on a Moving Film of Asphalt (Rolling Thin-Film Oven Test)". ASTM International, 2012.

17. T.W. Kennedy, et al., Superior performing asphalt pavements (Superpave): The product of the SHRP asphalt research program. Strategic Highway Research Program, National Research Council, Report No. SHRP-A-410, 1994. 